\title{
Meeting Report
}

\section{The World Summit of Harmonization on Traditional, Alternative and Complementary Medicine (TACM) in Lima, Peru}

\author{
Gustavo F. Gonzales ${ }^{1}$, José Aguilar ${ }^{1}$ and Martha Villar $^{2}$ \\ ${ }^{1}$ Faculty of Sciences and Philosophy, Universidad Peruana Cayetano Heredia, PO Box 4314, Lima 100 and \\ ${ }^{2}$ EsSalud, Lima, Peru
}

The World Summit of Harmonization on Traditional, Alternative and Complementary Medicine (TACM) was held in Lima, Peru, November 7-11, 2007, with almost 600 worldwide participants. This meeting was organized by Peruvian Medical College, the institution that affiliates and authorizes all physicians to practice medicine in Peru. The meeting included seven sections starting with an overview on the current status of the TACM. The second section included experiences from different countries on regulations and quality control in products and services used in the TACM. The worldwide experience of education and training in TACM was a very important part of the meeting in which speakers from Spain, Germany, Argentina, Italy, Brazil, Cuba and Peru shared their experience. The meeting included topics on homeopathy, acupuncture, mind-body medicine, neural therapy, chiropraxis, among others. Two final sessions were related to the ways of linking Traditional medicine to the national Health Systems in the Latin America countries and also the association between bio-commerce and TACM including intellectual properties and bio-piracy.

Keywords: TACM - traditional medicine - world summit

The World Summit of Harmonization on Traditional, Alternative and Complementary Medicine (TACM) was held in Lima, Peru, November 7-11, 2007. A welcome message was delivered by Dr Xiaouri Zhang, Director from the TACM program at the World Health Organization (WHO). This meeting was organized by Peruvian Medical College, the institution that affiliates and authorizes all physicians to practice medicine in Peru.

Peru is a classical example in which traditional medicine is broadly used since ancient times. This is revealed in many papers in the scientific literature showing the use of traditional medicine in particular with medicinal plants in the coast (1-6), the Andean region (7-10) and the Amazonian (9-21).

Peru has also contributed with several natural resources used as food, like potato or for treating diseases.

For reprints and all correspondence: Gustavo F. Gonzales, Faculty of Sciences and Philosophy, Universidad Peruana Cayetano Heredia, PO Box 4314, Lima 100, Peru. Tel: +00511 3190000 (2535); Fax: + 00511 3821762; E-mail: ggr@upch.edu.pe
For instance, the Cinchona tree-Cinchona calisayahas provided quinine, a product that was used in the past to treat malaria $(22,23)$. Quinine, an alkaloid derived from the bark of the cinchona tree was brought to Europe from Peru in the 17th century. Isolation of quinine and other cinchona alkaloids was achieved in France in the early part of the 19th century and uncertainties of supply of the bark stimulated efforts to synthesize quinine (23). Actually many Peruvian plants have been assessed to important health problems as tuberculosis $(24,25)$, inflammatory diseases (26) and cancer $(9,27)$.

The use of TACM has expanded broadly in the world, and this has been recognized by WHO. However, the indiscriminate, sometimes irresponsible or non-regulated use of several alternative therapeutic methods put in risk the health of the population using these medicines (14). For such reason a worldwide consensus is needed for harmonization in research, training and regulation of TACM. Then, based on this, the Peruvian Medical College organized the world summit in order to gather and 
share information and to learn from other countries where regulations of TACM are more developed.

The meeting included seven sections starting with an overview on the current status of the TACM. The second section included experiences from different countries on regulations and quality control in products and services used in the TACM. The worldwide experience of education and training in TACM was a very important part of the meeting in which speakers from Spain, Germany, Argentina, Italy, Brazil, Cuba and Peru shared their experience. In the University of Zaragoza, Spain, TACM teaching is observed at the School of Medicine, School of Nursing and in Postgraduate programs. In Germany, university teaching of TACM started in the late seventies. Argentina is working to promote the incorporation of TACM in the curriculum of Medical School. In the Medical Faculty of the State University of Milan a postgraduate course on TACM exists since 1993. In Campinas, Brazil, research and seminars on TACM are additionally offered to students of different careers. In Camaguey, Cuba, teaching in TACM is formal in postgraduate courses and as specialty for physicians. In Peru at the San Marcos University, a program on TACM is performed since 2001 .

An important component for the traditional medicine is the scientific demonstration that properties claimed for different therapeutic methods are valid. Then, this world summit included three sessions based on scientific evidence in TACM, clinical applications of TACM and proposal for criteria and methodologies in TACM research. Experts from France, Germany, Ecuador, Venezuela, Colombia, China, United States and Peru contributed to these sessions. One significant contribution was from Edwin Cooper, distinguished Professor from the Laboratory of Comparative Neuroimmunology, University of California, USA. Prof. Cooper demonstrated that TACM when rigorous can be science (28). Another topic of interest was presented by Dr Carmen Tamayo (Venezuela/USA) whose presentation was oriented to new methods and challenges when searching for evidence in TCAM. Finally in this session, Dr Gustavo Gonzales presented a model of scientific development with a natural Peruvian product currently under intense investigation.

It is known that traditional medicine not only deals with the knowledge and application of medicinal plants, but with a variety of strategies traditionally developed with the purpose to obtain the human well-being; thus, the meeting included topics on homeopathy, acupuncture, mind-body medicine, neural therapy, chiropraxis, among others. It is important to distinguish what does Traditional medicine means. In contemporary Western medicine 'traditional medicine' meant to refer to the Western medical tradition, whereas 'non-traditional medicine' encompasses both 'complementary' and 'alternative' medical practices. Complementary medicine complements conventional medical treatments, and alternative modes of medical interventions are meant to replace traditional Western medicine. Evidence-based research must be directed at establishing the best available evidence in complementary and alternative medicine (29). For each country, there is a traditional medicine. When this medicine is used in another places are considered as 'complementary' or 'alternative'. The importance of TACM has emphasized in four excellent articles from Olalde Rangel $(30-33)$.

Two final sessions were related to the ways of linking Traditional medicine to the National Health Systems in the Latin America countries and also the association between bio-commerce and TACM including intellectual properties and bio-piracy. The first was co-ordinated by the Andean Organism of Health in charge of Dr Oscar Feo (Venezuela). In Brazil, TACM is incorporated in the Primary Health Care. The current diagnosis and trends of TACM in Colombia was made in 2006. This will serve as reference by policy-makers, stake-holders, administrators and users. In Chile, TACM has been gradually incorporated in the last years through the Ministry of Health. In Mexico, TACM has been fully incorporated into the Mexican Constitution, General Law of Health and in the National health Plans 2007-12.

The best poster was awarded to Celine Valadeau et al. in a collaborative study from the Institute of Research for Development (IRD), France, the Universidad Nacional Mayor de San Marcos (Lima, Peru) and the community of San Peter in Pichanaz (Oxapampa, Peru). Ethno medicinal information from 600 plants from the central jungle in Peru close to the Andean region was recorded. It is an interesting fact that Traditional medicine in this population shares characteristics from the Traditional medicine in the Andean and Amazonian regions.

In conclusion, this meeting was successful since more than 600 people - most of them with medical degreeattended the meeting, with great interaction between audience and speakers. The Peruvian Traditional Medicine is recognized since the Peruvian Medical College created the Committee of TACM in 2006, headed by Dr Martha Villar, a physician recognized by her expertise in traditional medicine. The Committee is also comprised of Rosario Rojas, José Luis Aguilar, Carlos Corbacho, GustavoFGonzales, Ciro Maguiña, Hugo Malaspina and Oscar Villavicencio. The wide traditional use of medicinal plants is also recognized in Peru, however, there is still a lack of reliable scientific data $(2,5,7-11,13,15,17,18$, 25-27). This may produce situations in which products with long tradition can be commercialized for uses completely different from the original traditional use.

The importance of scientific research to demonstrate properties from medicinal plants is recognized. One example is the Peruvian Andean plant Lepidium meyenii (Maca) cultivated for longer than 1000 years in the highlands of Peru, which is appreciated by its nutritional, energizer and fertility-enhancing properties (9). This plant 
was in danger of extinction during the eighties of the past century. Despite of the long time of cultivation and that traditional knowledge on its properties was written since XVII century (9), the first scientific publication in a peer review journal on biological property of maca appeared in 2000 (34), and more than 20 Peruvian studies on Maca have been published in international journals from 2001 up to date $(9,35,36,37)$. From 1999 to 2001, there was observed a reduction in the production and exportation of maca. However, since the dates of the scientific publications, production of maca increased over time up to 2007 (35).

The necessity of including traditional medicine in the programs of the medical schools, to increase research and publications were raised during the discussion of the World Summit.

It is important to note that several congresses with a characteristic of this world summit have been developed worldwide during the last decade. This is important because it allows to increase the knowledge on evidence generation for CAM. One important issue is to maintain the sustainability of these meetings. For such reason, the next step will be to build an international network for continuously met and evaluate advances in TCAM in different countries. Next meeting will be held in Brazil in 2009.

As end part of the meeting, a Declaration was developed with several recommendations.

\section{Declaration of Lima}

The participants, governmental representatives, universities, related institutions and the civil society, heralding from more than 20 countries of Europe, Asia and America, met in the city of Lima, Peru during the World Summit for Harmonization of TACM, organized by the Peruvian Medical Association (CMP). Following a number of presentations and deliberations in different aspects, features and subjects of TACM, with the objective of informing governmental authorities and the global scientific community the group decided to summarize the conclusions of the meeting in the following 'Declaration of Lima'.

\section{Considering}

- that, traditional medicine is used by a great part of the world population, and it is accepted that the development of new therapeutic alternatives based on traditional medicine knowledge are needed, then, it is necessary to look for the harmonization of both conventional and traditional medicine approaches, with the purpose of improving Public Health worldwide;
- that, in the last decades, the practice and use of TACM has increased exponentially, having been recognized officially by the WHO as a form of medicine extensively used by the world population and with great possibilities of offering cost-effective alternatives for public health;

- that, the indiscriminate, irresponsible and unregulated use of diverse alternative and complementary therapeutic methods may lead to public-health risks and on the other hand, may also discredit an ancestral form of medicine with demonstrated effectiveness and relevance, when adequately used;

- that, TACM requires greater consensus in its organization, investigation, configuration and regulation and that it is necessary to appropriately integrate these aspects within the health care sector, involving the general population and urging the governments to be actively involved and change policies and strategies to improve health care;

- that, the benefits of the current health care systems, mainly based on conventional (Western) medicine, only reach a limited percentage of the population and since the resources assigned by the governments, especially in developing countries, are insufficient to cover health care expenses, it is necessary to harmonize and integrate both systems of medicine with their respective strengths: TACM in the promotion of healthy life styles, disease prevention and low-cost therapeutic interventions directed to diseases or conditions of low complexity, and conventional medicine in the solution of acute problems or diseases of higher complexity.

It is recommended:

(1) to acknowledge the existence of different models and medical systems and address the importance of studying their 'Cosmo vision', especially in the case of Traditional Medicine that should be better studied, investigated, valued, respected and promoted;

(2) to increase participation of all sectors in society. In health care, it is utterly important to have the participation of the government, citizens and health care communities, and all should actively contribute to the social process of health-disease;

(3) to acknowledge the existence of different health and health-care paradigms that, when articulated or joined in their common characteristics will allow a better understanding of the human being and the process of health-disease;

(4) to promote the articulation within the official systems of public health in each country, of TACM systems in order to improve the quality of life of their population, particularly because of the widespread use of TACM worldwide;

(5) to urge the Governments to assign greater resources and technical support for the expansion of their 
national systems of health, in order to integrate TACM and obtain a unique, cost-effective, population-based health care system;

(6) to promote the development and harmonization of the directives necessary for the implementation of the integration and articulation of TACM in each country, considering, formation of human resources, improvement in quality control and safety of products as well as increasing funds for research and endorsement;

(7) to sensitize and spread TACM knowledge among different sectors: health care managers, community, research and academic institutions and health professionals, through a variety of activities such as forums, symposiums, congresses and workshops; as well as to share experiences with countries around the world through exchange networks;

(8) to urge Universities and other academic institutions to include in its undergraduate and graduate curriculum the teaching of TACM and the validation of its knowledge and practices through research and pertinent activities;

(9) to be permanently alert, so that traditional knowledge and therapeutic natural resources are not the object of illegal appropriation, biopiracy or patent traffic, and to stimulate their recognition as a national patrimony and its fair economic value to the communities that use and preserve them;

(10) to promote that the processes of management, development, systematization and education of Traditional Medicine are carried out by those having recognition of their communities, supported by the government, the universities and the civil society. In that sense, respect to the environment, to the tangible and intangible resources of traditional Medicine, to the traditional knowledge and to its practitioners should be promoted;

(11) to develop and promote new approaches and methods of investigation and to implement strategies to obtain financial resources and train professionals that will contribute to the research, development and implementation of TACM;

(12) to promote the adequate, responsible and ethical use of TACM, avoiding illegal or fraudulent use and promote the dialogue between both conventional medicine and TACM practitioners in order to exchange knowledge and improve health care;

(13) to guarantee the continuity of similar TACM World Summits. An agreement was reached to organize and held biannual meetings in countries from different continents, designating Brazil as the venue for the next TACM World Summit to be held in 2009. An effort will be made to increase participation of government, academic and research institutions as well as regulators, scientists and practitioners from all over the world;
(14) to design adequate mechanisms that allow the diffusion, distribution, follow-up, evaluation and accomplishment of the recommendations of the 'Declaration of Lima'.

The present Declaration is signed, to substantiate the agreement reached by citizens interested in improving the health of the world population and the commitment to work in order that each point of this declaration is considered and implemented in the countries of the three continents represented.

Lima, November 11, 2007

\section{References}

1. Carod-Artal FJ, Vazquez-Cabrera CB. Sacred psychoactive seeds and ritual sacrifices in the Moche culture. Rev Neurol 2007;44:43-50

2. Bussmann RW, Sharon D. Traditional medicinal plant use in Northern Peru: tracking two thousand years of healing culture. $J$ Ethnobiol Ethnomed 2006;2:47.

3. Carod-Artal FJ, Vazquez-Cabrera CB. Mescaline and the San Pedro cactus ritual: archaeological and ethnographic evidence in northern Peru. Rev Neurol 2006;42:489-98.

4. De Feo V. Ethnomedical field study in northern Peruvian Andes with particular reference to divination practices. $J$ Ethnopharmacol 2003;85:243-56.

5. De-la-Cruz H, Vilcapoma G, Zevallos PA. Ethnobotanical study of medicinal plants used by the Andean people of Canta, Lima, Peru. J Ethnopharmacol 2007;111:284-94.

6. Dobkin de Rios M, Cardenas M. Plant hallucinogens, shamanism and Nazca ceramics. J Ethnopharmacol 1980;2:233-46.

7. Neto CC, Owens CW, Langfield RD, Comeau AB, Onge JS, Vaisberg AJ, et al. Antibacterial activity of some Peruvian medicinal plants from the Callejon de Huaylas. $J$ Ethnopharmacol 2002;79:133-8.

8. Hammond GB, Fernandez ID, Villegas LF, Vaisberg AJ. A survey of traditional medicinal plants from the Callejon de Huaylas, Department of Ancash, Peru. $J$ Ethnopharmacol 1998;61:17-30.

9. Gonzales GF, Valerio LG Jr. Medicinal plants from Peru: a review of plants as potential agents against cancer. Anticancer Agents Med Chem 2006;6:429-44.

10. Villegas LF, Fernandez ID, Maldonado H, Torres R, Zavaleta A, Vaisberg AJ, et al. Evaluation of the wound-healing activity of selected traditional medicinal plants from Peru. J Ethnopharmacol 1997;55:193-200.

11. Kloucek P, Svobodova B, Polesny Z, Langrova I, Smrcek S, Kokoska L. Antimicrobial activity of some medicinal barks used in Peruvian Amazon. J Ethnopharmacol 2007;111:427-9.

12. Lenaerts M. Substances, relationships and the omnipresence of the body: an overview of Asheninka ethnomedicine (Western Amazonia). J Ethnobiol Ethnomed 2006;2:49.

13. Kvist LP, Christensen SB, Rasmussen HB, Mejia K, Gonzalez A. Identification and evaluation of Peruvian plants used to treat malaria and leishmaniasis. J Ethnopharmacol 2006;106:390-402.

14. Arrevalo G. Interview with Guillermo Arrevalo, a Shipibo urban shaman, by Roger Rumrrill. Interview by Roger Rumrrill. J Psychoactive Drugs 2005;37:203-7.

15. Kloucek P, Polesny Z, Svobodova B, Vlkova E, Kokoska L. Antibacterial screening of some Peruvian medicinal plants used in Calleria District. J Ethnopharmacol 2005;99:309-312.

16. Jovel EM, Cabanillas J, Towers GH. An ethnobotanical study of the traditional medicine of the Mestizo people of Suni Mirano, Loreto, Peru. J Ethnopharmacol 1996;53:149-56.

17. Rojas R, Bustamante B, Bauer J, Fernandez I, Alban J, Lock O. Antimicrobial activity of selected Peruvian medicinal plants. J Ethnopharmacol 2003;88:199-204. 
18. Williams JE. Review of antiviral and immunomodulating properties of plants of the Peruvian rainforest with a particular emphasis on Una de Gato and Sangre de Grado. Altern Med Rev 2001;6:567-79.

19. Desmarchelier C, Gurni A, Ciccia G, Giulietti AM. Ritual and medicinal plants of the Ese'ejas of the Amazonian rainforest (Madre de Dios, Peru). J Ethnopharmacol 1996;52:45-51.

20. Dobkin de Rios M. A modern-day shamanistic healer in the Peruvian Amazon: pharmacopoeia and trance. J Psychoactive Drugs 1989;21:91-99.

21. Luna LE. The concept of plants as teachers among four mestizo shamans of Iquitos, northeastern Peru. $J$ Ethnopharmacol 1984;11:135-56.

22. Brick JE. Quinine: the conquest of malaria and the beginning of the modern drug industrial complex. $W V$ Med $J$ 1999;95:64-5.

23. Greenwood D. The quinine connection. J Antimicrob Chemother 1992;30:417-27.

24. Oeser CC, Escombe AR, Gilman RH, Friedland JS, Evans CA Moore DA. Does traditional medicine use hamper efforts at tuberculosis control in urban Peru? Am J Trop Med Hyg 2005;73:571-5.

25. Graham JG, Pendland SL, Prause JL, Danzinger LH, Schunke Vigo J, Cabieses F, et al. Antimycobacterial evaluation of Peruvian plants. Phytomedicine 2003;10:528-35.

26. Aguilar JL, Rojas P, Marcelo A, Plaza A, Bauer R, Reininger E, et al. Anti-inflammatory activity of two different extracts of Uncaria tomentosa (Rubiaceae). J Ethnopharmacol 2002;81:271-76.

27. Shaw T. Peru tries vinegar against cervical cancer. Bull World Health Organ 2003;81:73-4.

28. Cooper EL. Complementary and Alternative Medicine, When Rigurous, can de Science. Evid Based Complement Alternat Med 2004:1:1-4.
29. Chiappelli F, Prolo P, Cajulis OS. Evidence-based research in complementary and alternative history. Evid Based Complement Alternat Med 2005;2:453-8.

30. Olalde Rangel JA. The systemic theory of living systems and relevance to CAM: Part I: The theory. Evid Based Complement Alternat Med 2005;2:13-8.

31. Olalde Rangel JA. The systemic theory of living systems and relevance to CAM: Part II: The theory. Evid Based Complement Alternat Med 2005;2:129-37.

32. Olalde Rangel JA. The systemic theory of living systems and relevance to CAM: Part III: The theory. Evid Based Complement Alternat Med 2005:2:267-75.

33. Olalde Rangel JA. The Systemic Theory of Living Systems. Part IV: Systemic Medicine--The Praxis. Evid Based Complement Alternat Med 2005;2:429-39.

34. Zheng BL, He K, Kim CH, Rogers L, Yu S, Huang ZY, et al Effect of a lipidic extract from Lepidium meyenii on sexual behavior in mice and rats. Urology 2000;55:598-602.

35. Gonzales GF, Rubio J, Gasco M, Yucra S, Gonzales C. Lepidium meyenii, Maca, a plant from the highlands of Peru: pharmacological properties and impact on production and exportation. Proceedings of the 9th International Congress on Ethnopharmacology, NanningChina 2006:12-33.

36. Gonzales GF. Lepidium meyenii, Maca, a plant from the highlands of Peru: Biological properties. In: Zaheer Ahmed, Asha (eds). Advances in Natural Products: Importance in Health and Economy. Delhi: Centre for Science and Technology of the Non-Aligned and Other Countries, 2008, 69-75.

37. Canales M, Aguilar JL, Prada A, Huamán C, Marcelo A, Carbajal L. Evaluación Nutricional de Lepidium meyenii en ratones albinos y su descendencia. Arch Latinoam Nutr 2000;50:123-37.

Received March 6, 2008; accepted May 15, 2008 


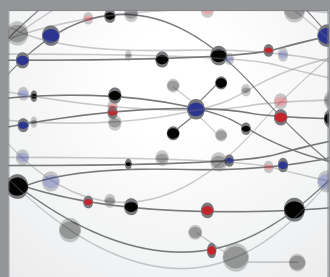

The Scientific World Journal
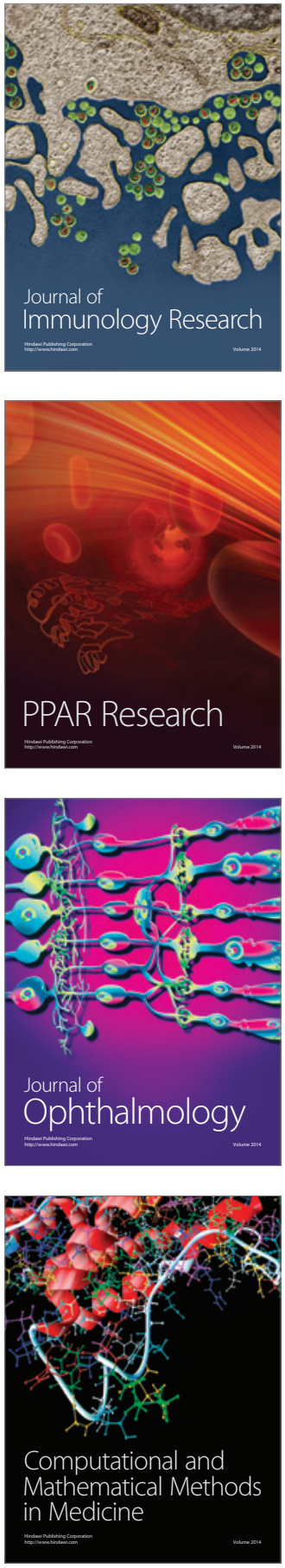

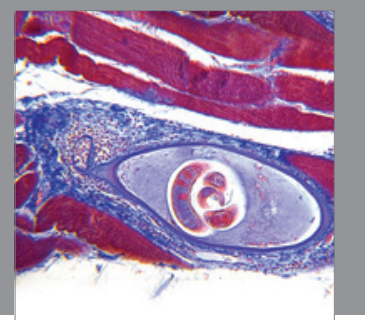

Gastroenterology

Research and Practice
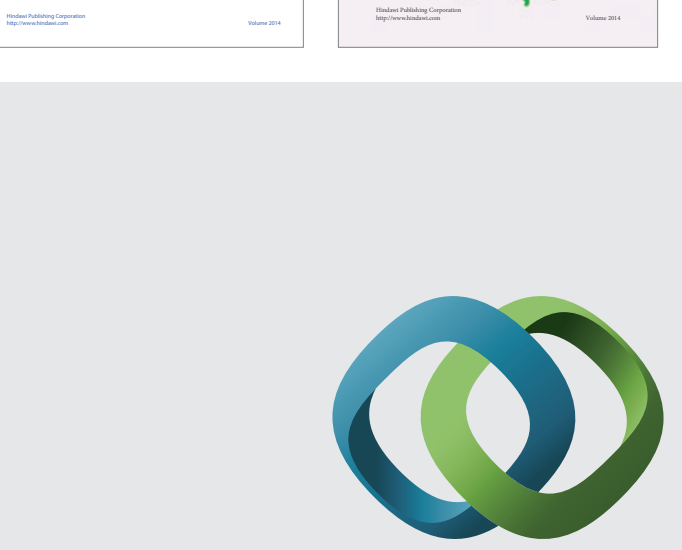

\section{Hindawi}

Submit your manuscripts at

http://www.hindawi.com
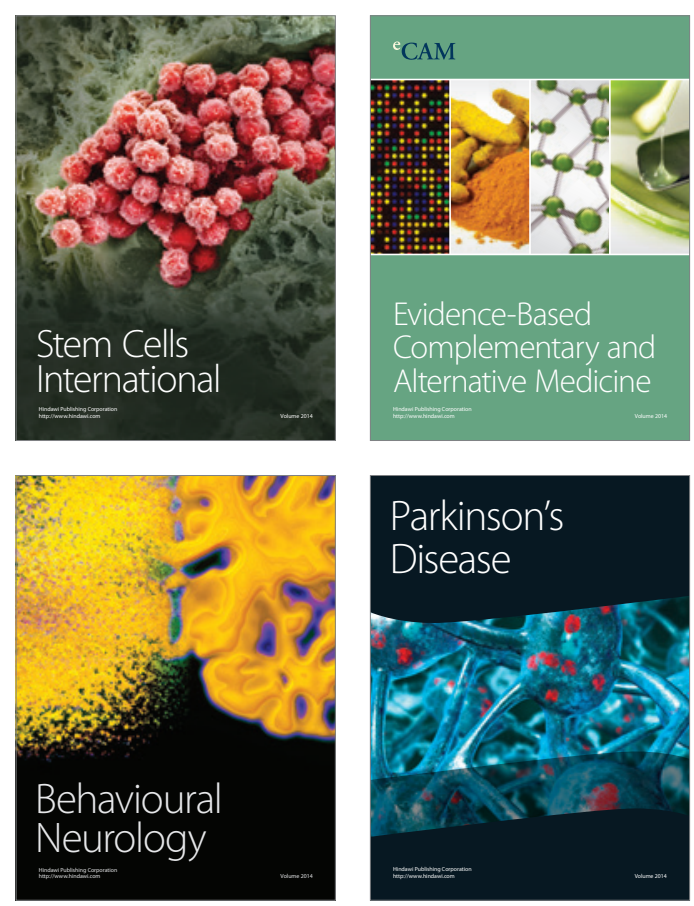

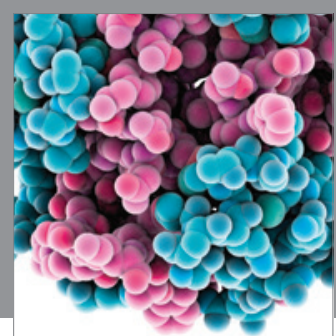

Journal of
Diabetes Research

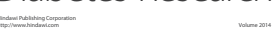

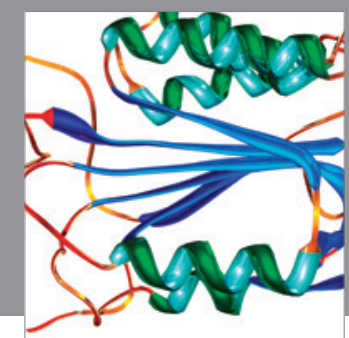

Disease Markers
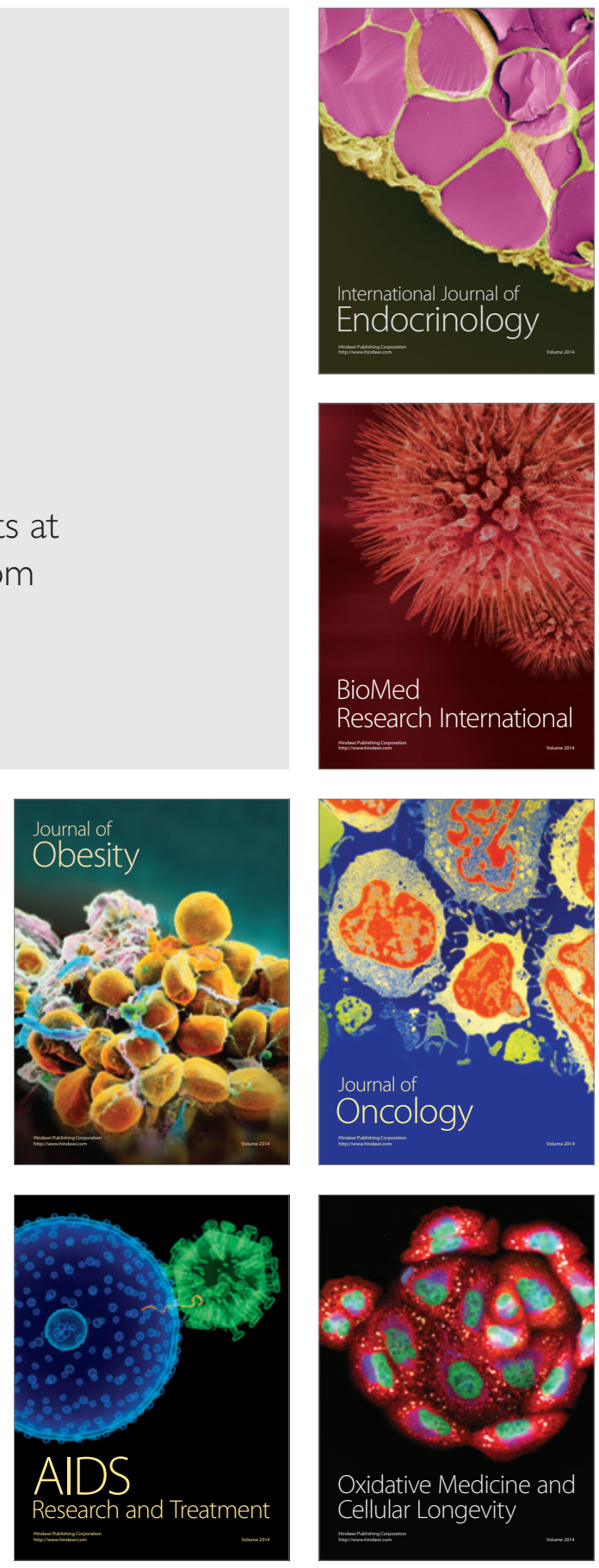